\title{
Microscopy after Colonoscopy: an Institutional experience in India
}

\author{
Chaitanya $B^{1}$, Ramakrishna BA ${ }^{2}$, Shanthi $V^{3}$, Reddy $\mathrm{SR}^{4}$ \\ ${ }^{1}$ Dr Balekuduru Chaitanya*, ${ }^{2}$ Dr B A Ramakrishna*, ${ }^{3}$ Dr Vissa Shanthi*, ${ }^{4}$ Dr S Rajasekhar Reddy\#. *All are affiliated with Dr \\ NTR University of Health sciences, Vijayawada, Andhra Pradesh, India. "Affiliated with Nizam's Institute of Medical Sciences \\ Hyderabad, Andhra Pradesh, India
}

Address for Correspondence: Dr. Balekuduru Chaitanya, Email: bharadwaj.chaitanya@yahoo.com

\begin{abstract}
Objectives: To study the histopathological features of mucosal and resected biopsy specimens for etiological diagnosis and comment on the extent, activity and severity of colonic lesions wherever possible by histological examination and correlate with the clinical diagnosis provided. Methods: Consecutive colonic biopsy/resected specimens received during a period of two years were included in this study. Clinical details with laboratory results were correlated with the pathological findings. Results: 124 mucosal biopsies and 56 resected specimens were included in this prospective study. Of 180 patients, 118(65.5\%) were men. All age groups from 2-90 years were included in the study. Majority constituted 51-60 years (27.2\%). Rectal bleeding was the most common presentation (71.1\%) followed by constipation (48.9\%). Two patients had normal mucosal biopsy, neoplastic lesion was noted in 78(43.3\%) and the remaining majority 100 (55.5\%) had non neoplastic etiology. Among non-neoplastic etiology, chronic non-specific colitis was the most common diagnosis (56\%) followed by ulcerative colitis (17\%) and ischemic colitis (10\%). In benign lesions, inflammatory polyps (37.5\%) were the commonest followed by tubular $(40 \%)$ and villous adenomas $(10 \%)$. Adenocarcinoma was the commonest neoplastic lesion noted in $95 \%$ of the patients. Rectum and cecum were the common sites of abnormality. Multiple deep biopsies that the relationship between tumour and stroma could be properly assessed as well as routine biopsies were adequate in $98.9 \%$ of the cases. Conclusion: The study was made as an effort to bring into light the spectrum of colonic lesions in a teaching hospital in South India.
\end{abstract}

Key words: Colorectal Carcinoma, Colonoscopy, Histopathology

\section{Introduction}

The large intestine or the colon measures approximately 150 $\mathrm{cms}$ in the adult. The lining epithelium is subject to a wide variety of insults ranging from inflammatory, infectious to neoplastic processes. With the advent of colonoscopy as an investigative modality, prompt diagnosis with early therapeutic intervention and screening has become possible in the management of colonic lesions. Ever since its inception the rapidly expanding spectrum of indications for colonoscopy have been classified broadly as diagnostic and therapeutic. Its intraluminal imaging ability has been extensively used for surveillance of inflammatory bowel disease, benign polyps after resection and colorectal cancer.

Therapeutically colonoscopy is often employed for treatment of bleeding lesions, removal of a foreign body or polyp, balloon dilatation of stenotic lesions and localization of malignancies. Its diagnostic value is duly supported by pathological evaluation of extracted mucosal biopsy

Manuscript received: $24^{\text {th }}$ Dec 2013

Reviewed: $29^{\text {th }}$ Dec 2013

Author Corrected: $15^{\text {th }}$ Jan 2014

Accepted for Publication: $18^{\text {th }}$ Jan 2014 specimens. Colonoscopic mucosal biopsies are valuable to

1) Document normal colonic mucosa.

2) Identify inflammatory processes in endoscopically normal appearing colonic mucosa.

3) Identify and discriminate different inflammatory reaction patterns.

4) Separate diseases with similar histological reaction patterns but distinct distribution patterns.

5) Suggest the possibility of more than one disease process (e.g., ulcerative colitis complicated by infection or Clostridium. Difficile overgrowth).

6) Identify, albeit rarely, a specific causative agent (e.g., cytomegalovirus) [1].

Any specimen being sent to the pathologist for histological diagnosis should be accompanied by pertinent clinical history, endoscopic/ intra operative findings. Precise staging 


\section{Short Communication}

helps to plan adjuvant therapy which can help in improving disease free and overall survival.

Grading is a pathological marker of aggressive biology which is used to sub- categorize patients.

This study is undertaken to concentrate on the uses of mucosal and resected specimen analysis so as to provide valuable insights in to colonic pathology.

The specific objectives were as follows:

- To provide a diagnosis and comment on the extent, activity and severity of colonic lesions wherever possible by histological examination.

- To classify according to etiopathology wherever possible and emphasize on the prevalence of colonic malignancy.

\section{Results}

A total of 180 biopsy specimens could be recruited for the study during the study period (2010-2012). All had colonoscopic mucosal biopsies but 54 specimens had repeat surgically resected gross specimens for the study.

The mean age of the group was 54 years (range 2-90 years) and majority were men (65\%).

The most common symptom was bleeding per rectum affecting 128 (71.1\%) patients followed by constipation 88 (48.9\%), abdominal pain $80(44.4 \%)$, fatigue $68(37.8 \%)$ and diarrhea in $65(36.1 \%)$.

Colonoscopic findings revealed solitary and multiple lesions in $126(70 \%)$ and $50(27.7 \%)$ patients, respectively.

On the basis of appearance, $126(70 \%)$ of the lesions were ulcerative while $54(30 \%)$ were ulceroproliferative/nodular. Three $(3 \%)$ patients had erythematous mucosa only while one patient had telangectatic spots.

\section{Table 1: Non-Neoplastic Lesions}

\begin{tabular}{|l|l|l|l|}
\hline S. No. & Diagnosis & Number of Cases & Percentage \\
\hline 1 & Infective Colitis & 02 & $02 \%$ \\
\hline 2 & Tuberculosis & 08 & $08 \%$ \\
\hline 3 & Amoebiasis & 02 & $02 \%$ \\
\hline 4 & Chronic Non-Specific Colitis & 56 & $56 \%$ \\
\hline 5 & Ischaemic Colitis & 10 & $10 \%$ \\
\hline 6 & Ulcerative Colitis & 17 & $17 \%$ \\
\hline 7 & Crohn's Disease & 02 & $02 \%$ \\
\hline 8 & Foreign body Granulomas & 03 & $03 \%$ \\
\hline & Total & 100 & $100 \%$ \\
\hline
\end{tabular}

The mucosal biopsies revealed predominantly non neoplastic lesions in 100(55.56\%) followed by neoplastic lesions in $78(43.33 \%)$ and normal biopsies were noted in remaining 2 specimens $(1.11 \%)$.

Among non neoplastic lesions, chronic non-specific colitis was the most common diagnosis (56\%) followed by ulcerative colitis $(17 \%)$ and ischemic colitis (10\%). (Table 1) 
Table 2: Benign Neoplastic Lesions

\begin{tabular}{|l|l|l|l|l|}
\hline S. No. & Lesion & Number of Cases & Percentage & Dysplasia \\
\hline 1 & Inflammatory Polyps & 15 & $37.5 \%$ & $3(7.5 \%)$ \\
\hline 2 & Hyperplastic Polyps & 2 & $5 \%$ & $1(2.5 \%)$ \\
\hline 3 & Transitional Polyps & 1 & $2.5 \%$ & - \\
\hline 4 & Juvenile Polyps & 1 & $2.5 \%$ & - \\
\hline 5 & Lipomatous Polyps & 1 & $2.5 \%$ & - \\
\hline 6 & Tubular Adenomas & 16 & $40 \%$ & $3(7.5 \%)$ \\
\hline 7 & Villous Adenomas & 4 & $10 \%$ & $4(10 \%)$ \\
\hline
\end{tabular}

In benign lesions, inflammatory polyps (37.5\%) were the commonest followed by tubular (40\%) and villous adenomas (10\%). (Table2)

Table 3: Malignant Neoplastic Lesions

\begin{tabular}{|l|l|l|l|}
\hline S. No. & Lesion & Number of Cases & Percentage \\
\hline 1 & Well differentiated adenocarcinoma & 24 & $63.16 \%$ \\
\hline 2 & Moderately differentiated adenocarcinoma & 5 & $13.16 \%$ \\
\hline 3 & Poorly differentiated adenocarcinoma & 1 & $2.63 \%$ \\
\hline 4 & Mucinous adenocarcinoma & 6 & $15.79 \%$ \\
\hline 5 & Squamous cell carcinoma & 1 & $2.63 \%$ \\
\hline 6 & Neuroendocrine Carcinoma & 1 & $2.63 \%$ \\
\hline & Total & 38 & $100 \%$ \\
\hline
\end{tabular}

Adenocarcinoma was the commonest neoplastic lesion noted in $95 \%$ of the patients (Table 3).

Table 4: Location of Adenocarcinomas

\begin{tabular}{|l|l|l|l|l|l|}
\hline S. No. & Site & Well - Diff. & Mod. - Diff & Poorly - Diff & Mucinous \\
\hline 1 & Caecum & $5(20.82 \%)$ & $1(20 \%)$ & & $2(33.34 \%)$ \\
\hline 2 & Ascending Colon & $3(12.50 \%)$ & $1(20 \%)$ & & $1(16.67 \%)$ \\
\hline 3 & Transverse Colon & $1(4.17 \%)$ & & & \\
\hline 4 & Descending Colon & - & & & \\
\hline 5 & Sigmoid Colon & $4(16.67 \%)$ & $2(40 \%)$ & & $1(16.67 \%)$ \\
\hline 6 & Rectosigmoid & $4(16.67 \%)$ & & & $1(16.67 \%)$ \\
\hline 7 & Rectum & $7(29.17 \%)$ & $1(20 \%)$ & $1(100 \%)$ & $1(16.67 \%)$ \\
\hline & Total & $24(100 \%)$ & $5(100 \%)$ & 1 & $6(100 \%)$ \\
\hline
\end{tabular}

Rectum and cecum were the common sites of abnormality (Table 4).

Multiple deep biopsies that the relationship between tumour and stroma could be properly assessed as well as routine biopsies were adequate in $98.9 \%$ of the cases.

\section{Discussion}

This report represents the first study to characterize the profile of pathological colonic specimens in symptomatic patients of South India. Although this is not a populationbased study, important data about the colorectal carcinoma in our sample of local population is presented. The current project is undertaken to study the frequency, age distribution and the pathological characteristics of the colonic problems in South India.
Twenty percent of the biopsies were colonic of which $55 \%$ were non neoplastic. Forty three percent were neoplastic but of them $48.7 \%$ were malignant. In our study colorectal malignancy accounted for $21.1 \%$ of the total biopsy specimens received.

Colorectal malignancy comprised of $5.4 \%$ of the total number of malignancies from urban population [2]. The 


\section{Short Communication}

colorectal cancer related mortality and morbidity stood at $4.5 \%$ and $4.1 \%$ respectively in Delhi urban population [3]. Though our numbers are small the colorectal malignancy in our study group is $21 \%$ related to the preferential low biopsies done in the endoscopy suite.

Colorectal carcinoma was the most common malignant GIT tumors, accounting for $53.52 \%$ of all GIT malignancies in this study.

This is similar to studies from other parts of world where it was found to represent between $53 \%-67 \%$ of all malignant GIT tumors [4, 5]. Even in the United States of America, it was reported to be the most common GIT cancer and the second leading cause of cancer death [6].

Peak age reported from our study ranged between 34 years to 85 years. The mean age in this study is 50.7 years which corroborates 44.3, 49.7, 51, and 52.3 years reported from Jos in Kenya, Egypt and Iran, respectively [7-9].

The age incidence of CRC in India is lower compared to developed countries; about 10 years difference has been reported in many studies $[10,11]$.

The presentation of the colonic disease is predominantly rectal bleed (71\%) followed by constipation (48\%) emphasizing the importance of history of alarm features in the diagnosis of colonic pathology.

There appears to be an increasing number of Colorectal carcinoma cases occurring in the young as $23.6 \%$ occurred below age 40 years while $2.6 \%$ occurred in patients 30 years and below in this study. Reports from other parts of world showed that $35 \%-42 \%$ of patients with CRC are below age 40 years $[10,11]$.

Colorectal carcinoma in younger age has been shown to present a diagnostic and therapeutic problem and prognosis tends to be less favourable [12].

In one study, Colorectal carcinoma in young females was reported to have more tendencies to present with a late stage disease and anemia [13]. A "left" to "right" sided or proximal shift of tumours has been reported in studies mostly from western countries.

Nevertheless, several other studies especially from Asia have shown no such shift. Our study shows that CRC is more common in the left colon $(61 \%)$ than in the right colon $(38 \%)[9,14-16]$.

The reason for increasing incidence may be genetic, thus underscoring the need to study the prevalence of HNPCC associated $\mathrm{CRC}$ in our environment.
On the other hand, it may be related to dietary factors since the young Indians tend to be more civilized and more likely take Westernized diet. In India, there has been a shift from the traditional Indian Thali diet, due to upsurge in the number of fast food outlets, and it has become fashionable particularly among the youths to eat these Westernized food which are high in animal protein and fat which are carcinogenic.

Among 100 non neoplastic lesions the most common etiology being chronic non- specific colitis in $56 \%$ also comprising the solitary rectal ulcer syndrome in 5 cases (three " lies" disease - not always solitary, not always ulcerated, not always in rectum). The non -specific colitis patients need to be followed by with repeat colonoscopy and biopsies so as to determine the actual etiology in the natural history of the disease process [17].

No gender differences were noted in our patients. The mean age of diagnosis in our cancer patients and patients with adenomatous polyps (in the 5th decade of life) is consistent with previously established data. Our cancer patients were more than 10 years older than patients with adenomatous polyps which is compatible with transformation of a polyp to cancer in a 10 -year period. The incidence of colorectal cancer increases with age. Risk of colorectal cancer increases with advanced age. This pattern was also observed in our study [18].

Older age is an independent predictor for polyp and cancer in our population.

Lower gastrointestinal symptoms are not predictive of colorectal neoplasia in our study as supported by reports from western countries. This may be explained simply by the frequency of lower gastrointestinal symptoms in the general population.

However, the rate of rectal bleeding in this study is considerably higher than that in the general population, while a possible explanation is that there is a high prevalence of benign disease likely to cause rectal bleeding. Unexplained anemia is the only sign which can predict Colorectal carcinoma $[19,20]$.

The characteristics of both patients and adenomas can influence the risk of carcinoma developing in colorectal adenomas. These are the age of the patient, size of the adenoma, its villous component and the severity of dysplasia [21].

Villous adenomas seem to be less common in our community compared with western countries, which may 
become malignant in $29 \%$ to $70 \%$ of the time [22]. The majority of polyps detected in our study population were tubular (40\%) and villous adenomas comprised 10\%. Thirty eight percent were inflammatory polyps.

The size of polyps has been reported as an independent predictor of malignancy in colorectal polyps. The risk of developing adenocarcinoma is $1 \%$ in adenomas of up to 1 $\mathrm{cm}$ in size, $10 \%$ in adenomas from $1 \mathrm{~cm}$ to $2 \mathrm{~cm}$ in diameter and $50 \%$ in those greater than $2 \mathrm{~cm}$ in diameter.

Only $4 \%$ of adenomas less than $6 \mathrm{~mm}$ diameter, and $16 \%$ of those between $6 \mathrm{~mm}$ and $10 \mathrm{~mm}$ are reported to have unfavorable histology. According to our results, $40.0 \%$ of polyps were less than $6 \mathrm{~mm}, 37.5 \%$ were between $6-10 \mathrm{~mm}$ and $22.5 \%$ were more than $10 \mathrm{~mm}$ which shows smaller groups at higher risk of malignancy [23, 24].

In the authors' experience in our region about anatomic sites of adenomatous polyps and Colorectal carcinoma (1992 to 2005), there is a predominant location of left side. The study was based on evaluation by colonoscopy and barium enema in patients with colorectal adenoma or Colorectal carcinoma. In the current study which is based on findings of total colonoscopy, more than $40 \%$ of polyps were located in the recto-sigmoid region while a shift to the right side was prominent in the sites of Colorectal carcinoma [25].

Although most cases of rectal bleeding were due to self limiting diseases in our study, the probability of colorectal cancer increases significantly both in people older than 50 years and in association with unexplained anemia indicating the need for a more thorough investigation in such cases.

Smaller size of adenomas, dominancy of tubular type and fewer cases with severe dysplasia among colorectal adenoma and lower incidence of cancer in our region compared with western populations is comparable with Asian populations and may suggest that it is not a serious health problem of our community at present. Although suspicious symptoms clearly call for urgent investigation, it is important to recognize lower gastrointestinal symptoms are not predictive of cancer except for rectal bleed, constipation and unexplained anemia in elderly patients.

\section{Conclusion}

This is the largest study to date from our center, comparing the pathological specimens which by nature is a prospective study of 180 biopsy specimens over 2 year study period. This study was conducted with an academic purpose to effectively enhance health communication and to bring awareness of the patterns of colonic lesions in a South Indian teaching hospital so as to enhance the scholarly discipline of Gastroenterological Pathology.

\section{Funding: Nil \\ Conflict of interest: Nil \\ Permission from IRB: Yes}

\section{References}

1. Herschel A. Carpenter, Nicholas J.Talley. The importance of clinicopathological correlation in diagnosis of inflammatory conditions of colon: Histological patterns with clinical implications. Am J Gastroenterol.2000;95 (4):878-896.

2. Dr. P.S. Prabhakaran POPULATION BASED CANCER REGISTRY, BANGALORE Kidwai Memorial Institute of Oncology, Bangalore Individual Registry Data: 1990-1996.

3. Vinod Raina, Tyagi M, Manoharan DELHI CANCER REGISTRY. CANCER INCIDENCE AND MORTALITY IN DELHI UT URBAN - 2002 \& 2003 published in 2007.

4. Okobia MN, Aligbe JU. . Pattern of malignant diseases at the University of Benin Teaching Hospital. Trop Doct.2005;35(2):91-92.

5. Holcombe C, Babayo U. The pattern of malignant disease in north east Nigeria. Trop Geogr Med. 1991;43:189-192.

6. American Cancer Society. Cancer Facts and Figures: Special Edition 2005. Atlanta: American Cancer Society, 2005. Available from: URL: http:/www.cancer.org/downloads/STT/CAFF2005CR4PW Secured.pdf.

7. Saidi H, Nyaim EO, Githaiga JW, Karuri D. CRC surgery trends in Kenya, 1993-2005. World J Surg. 2008:32(2):217223.

8. El-Bolkainy TN, Sakr MA, Nouh AA, El-Din NH. A comparative study of rectal and colonic carcinoma: demographic, pathologic and TNM staging analysis. J Egypt NatlCanc Inst. 2006:18(3):258-263.

9. Fazeli MS, Adel MG, Lebaschi AH. Colorectal carcinoma: a retrospective, descriptive study of age, gender, subsite, stage, and differentiation in Iran from 1995 to 2001 as observed in Tehran University. Dis Colon Rectum. 2007:50(7):990-995.

10. Ojo OS, Odesanmi WO, Akinola OO. The surgical pathology of colorectal carcinomas in Nigerians. Trop Gastroenterol. 1992;13:64-69. 


\section{Short Communication}

11. Adesanya AA, da Rocha-Afodu JT. Colorectal cancer in Lagos: a critical review of 100 cases. Niger Postgrad Med J. 2000;7:129-136.

12. Sule AZ, Mandong BM. Malignant colorectal tumours in patients 30 years and below: a review of 35 cases. Cent Afr J Med. 1999:45(8):209-212.

13. Olofinlade O, Adeonigbagbe O, Gualtieri N, Freiman H, Ogedegbe O, Robilotti J. Colorectal carcinoma in young females. South Med J. 2004:97(3):231-235.

14. Scheiden R, Pescatore $\mathrm{P}$, Wagener $\mathrm{Y}$, Kieffer $\mathrm{N}$, Capesius C. Colon cancer in Luxembourg: a national population-based data report, 1988-1998. BMC Cancer. 2005;5:52.

15. Goh KL, Quek KF, Yeo GT, Hilmi IN, Lee CK, Hasnida N, Aznan M, Kwan KL, Ong KT. Colorectal cancer in Asians: a demographic and anatomic survey in Malaysian patients undergoing colonoscopy. Aliment PharmacolTher. 2005:22(9):859-864.

16. Gomez D, Dalal Z, Raw E, Roberts C, Lyndon PJ. Anatomical distribution of colorectal cancer over a 10 year period in a district general hospital: is there a true “rightward shift”? Postgrad Med J. 2004:80(949):667-669.

17. L. Crespo Pérez, V. Moreira Vicente, C. Redondo Verge1, A. López San Román and J. M. MilicuaSalamero "The three-lies disease": Solitary rectal ulcer syndrome REV ESP ENFERM DIG 2007; 99 (11): 663-666.
18. Ahmed S, Leslie A, Thaha MA, Carey FA, Steele RJ. Lower gastrointestinal symptoms are not predictive of colorectal neoplasia in a faecal occult blood screen-positive population. Br J Surg. 2005:92(4):478-481.

19. Wynder EL, Reddy BS. Epidemiology of cancer of the colon. In: Levin DL, editor. Cancer Epidemiology in the USA and USSR. Maryland: National Institutes of Health Publication NO 20-2044; 1980. Pp. 81-86.

20. Loy TS, Kaplan PA. Villous adenocarcinoma of the colon and rectum: a clinicopathologic study of 36 cases. Am J SurgPathol. 2004:28(11):1460-1465.

21. Pickhardt PJ. The natural history of colorectal polyps and masses: rediscovered truths from the barium enema era. AJR Am J Roentgenol. 2007:188(3):619-621.

22. Bacon HE, Eisenberg SW. Papillary adenoma or villous tumor of the rectum and colon. Ann Surg. 1971:174(6):1002-1008.

23. Nusko G, Mansmann U, Altendorf-Hofmann A, Groitl H, Wittekind C, Hahn EG. Risk of invasive carcinoma in colorectal adenomas assessed by size and site. Int $\mathrm{J}$ Colorectal Dis. 1997:12(5):267-271.

24. Church JM. Clinical significance of small colorectal polyps. Dis Colon Rectum. 2004:47(4):481-485.

25. Bafandeh Y, Daghestani D, Esmaili H, Aharizad S. Distribution of cancer and adenomatous polyps in the colorectum: study in an Iranian population. Asian Pac J Cancer Prev. 2006:7(1):65-68.

\section{How to cite this article?}

Chaitanya B, Ramakrishna BA, Shanthi V, Reddy SR. Microscopy after Colonoscopy: an Institutional experience in India. Int J Med Res Rev 2014;2(2):92-97. doi:10.17511/ijmrr.2014.i02.04 